\title{
Temporal Changes in the Lesser Flamingos Population (Phoenicopterus minor) in Relation to Phytoplankton Abundance in Lake Manyara, Tanzania
}

\author{
Emilian Samwel Kihwele1, Charles Lugomela², Kim M. Howell² \\ ${ }^{1}$ Tanzania National Park, Arusha, Tanzania \\ ${ }^{2}$ University of Dar es Salaam, Dar es Salaam, Tanzania \\ Email: kihwele2001@yahoo.co.uk
}

Received 30 December 2013; revised 28 January 2014; accepted 7 February 2014

Copyright (c) 2014 by authors and Scientific Research Publishing Inc.

This work is licensed under the Creative Commons Attribution International License (CC BY). http://creativecommons.org/licenses/by/4.0/

(c) (i) Open Access

\section{Abstract}

A study on seasonal variations in the abundance of Lesser Flamingo (Phoenicopterus minor) in relation to phytoplankton abundance in lake Manyara was conducted for a period of fourteen consecutive months (July 2007 to August 2008). The aim was to relate the temporal variability in the phytoplankton species abundance and diversity of the lake to the population size of the Lesser Flamingo. Lesser Flamingo population numbers were obtained from monthly ground surveys whereby the lake was subdivided into defined counting vantage points. Water samples for phytoplankton species composition and biomass analyses were taken to the University of Dar es Salaam for laboratory analysis. The flamingo population estimates ranged from 9319 in August 2007 to 640,850 in $\mathrm{Au}$ gust 2008. The Lesser Flamingo populations showed that temporal fluctuations were related to the changes in the abundance and diversity of phytoplankton species. The occurrence of Arthrospira associated with the increase in the abundance of Lesser Flamingo. It was observed that changes in the Lesser Flamingo numbers were influenced by the changes in the abundance and availability of their preferred food. The results indicated that microalgae assemblage positively correlated with ammonium and nitrate which were also related to the abundance of lesser flamingo. The phytoplankton community was dominated by cyanobacteria particularly Arthrosipira fusiformis likely due to the high lake salinity and $\mathrm{pH}$ that limited the growth of other microalgae. Correlation analysis showed strong correlation between the Lesser Flamingo abundance with the concentration of nitrate and ammonium and between the number of Lesser Flamingo and the cyanobacterium Arthrospira.

\section{Keywords}

Arthrospira; Lake Manyara; Lesser Flamingo; Phytoplankton; Population 


\section{Introduction}

Lesser Flamingo occurs in three regions in sub-Saharan Africa. They are east Africa, southern Africa and west Africa (Brown et al., 1982 [1]; Del Hoyo, 1992 [2]; Mundkur, 1997 [3]). However, their distribution pattern is dynamic, changing with respect to availability of food and breeding cycles. The food availability is in turn affected by the quality and quantity of water. Brown and Root (1971) [4] reported that Lesser Flamingo exhibits unpredictable, spontaneous and sporadic nomadic movements to find lakes with adequate food supplies among the alkaline-saline lakes. This behavior is related mainly to changes in food quality and quantity. Ndetei and Muhandiki (2005) [5] observed that Lesser Flamingo populations in the Kenyan rift valley saline lakes, respond to changes in phytoplankton species composition and density, their own breeding cycles and environmental conditions.

The Lesser Flamingo feeds on plankton cyanobacteria and other microalgae species floating in the water column in eutrophic shallow habitats, such as saline lakes, saltpans, coastal mudflats, coastal lagoons, salt works and rivers/streams receiving water from sewage treatment works (Vareschi, 1978 [6]). Despite of Lesser Flamingo feeding on a variety of phytoplankton species (Vareschi, 1978 [6]; Tuite, 1979 [7]; Krienitz et al., 2003 [8]; Krienitz and Kotut, 2010 [9]), large numbers of this bird species have been observed in lakes where the cyanobacterium, Arthrospira fusiformis dominates the lake primary production (Vareschi, 1978 [6]; Tuite, 1979 [7]; Melack and Kilham, 1974 [10]).While small Lesser Flamingo numbers are usually found when these lakes are dominated by non-Arthrospira fusiformis cyanobacteria.

This is because Lesser Flamingo depends on soda lakes and wetland ecosystems for their survival. Recently, these ecosystems have been subjected to various human induced threats (Owino et al., 2002 [11]; Mlingwa and Baker, 2006 [12]), which are exacerbated by increased human population. For example Kihwele and Moronda (2004) [13] reported that human population in lake Manyara catchment basin has increased from 165,532 people in 1978 to 904,566 people in 2002. This rapid population growth was accompanied by an increase in agricultural activities, deforestation and expansion of settlements that highly affect the ecology of lake Manyara. According to Kihwele and Moronda (2004) [13], Nou and Marang catchment forest reserves, which are the key areas to the survival of lake Manyara, have decreased from 32,000 ha in 1933 and 35,000 ha in 1957 to 28,893.6 ha and 22,000 ha in 2004 respectively. These encroachments and reductions in the forest reserve areas are due to the establishment of new villages and expansion of settlements and agriculture as a result of poor governance. Negative impacts on the lake are likely to occur due to greater off take of water for irrigation, pollution by agricultural biocides, eutrophication from run-off and effluent as well as deforestation (Nonga, 2011 [14]).

The spectacular attractively, alkaline soda lakes of east Africa with their avifauna, the Lesser Flamingo form one of the most important tourist attractions, which is of great economical importance (Tebbs et al; 2011 [15]). These lakes also provide hydrological services that extend beyond the direct use values, and have a significant financial value associated with them (Acharya, 2000 [16]). These economical potentialities are adversely affected by unpredictable changes in flamingo population distribution as well as hydrological regimes, probably caused by cyclic changes in the water quantity and quality (TANAPA, 2005 [17]) of the lakes.

Lesser Flamingos are however, categorized by IUCN (2004) [18] as a nearly threatened species due to its localized distribution in specific habitats. They are threatened as a result of increasing degradation to their potential habitats through altered hydrology and water quality, wetland pollution and changes in the land use patterns. Currently the number of the Lesser Flamingos within east Africa is estimated to be between 1.5 and 2.5 million (Wetlands International, 2006 [19]), about a half of that formerly recorded in East Africa (Brown and Root, 1971 [4]; Bartholomew and Pennycuick, 1973 [20]; Brown, 1973 [21]; Nasirwa, 1994 [22]).

The decline in Lesser Flamingo population has raised concerns both in eastern and southern Africa. This decline has been associated with the degradations of the three known breeding sites, i.e., Lake Natron in Tanzania, Etosha Pan in Namibia and Sua Pan in Botswana (Nasirwa, 1997 [23]; Howard, 1997 [24]; Simmons, 2000 [25]; Wetland International, 2002 [26]; Birdlife International, 2004 [27]). Increased siltation and chemical pollution from mining and agricultural activities pose one of the major threats to most of these lakes. Thus the survival of the lakes depends on catchment wide basin activities such as sustainable agriculture and livestock grazing (Nonga, 2010 [28]).

An increased mortality rate in recent decades has contributed to the decreased numbers of the Lesser Flamingo in east Africa (IUCN-SSC, 2008 [29]), as their mortality is negatively impacting on the population size of the bird. Ndetei and Muhandiki (2005) [5] reported that there have been repeated, unpredictable episodes of Lesser 
Flamingo mortalities in the Kenyan rift valley lakes of which their cause has been attributed to cyanobacteria toxins and reduced water levels caused by catchment development and climate variability. Moreover, Harper et al., (2003) [30] also reported that three large mortalities of Lesser Flamingo that occurred in Kenyan lakes in the previous decades are currently further threatening the Lesser Flamingo population. For example, in the year 2000 an estimated number of over 30,000 birds died in lake Bogoria, Kenya (Vick 2000 [31]). In Tanzania, Lesser Flamingo deaths had not been reported until 2003 (N. Magoma, personal communication) when about 800 birds died at lake Empakay. Also, between July and August 2004, 43,850 dead flamingo were counted in lake Manyara while an estimate of 1050 deaths were reported at lake Big Momela in Arusha National Park during the same period (TANAPA, 2005 [17]).

The decline in the number of Lesser Flamingo is been revealed from the existing census data. Within east African range of the Lesser Flamingo habitats, a number of censuses in various rift valley lakes dating back to the 1960's have been conducted by various researchers (Brown, 1959 [32]; Grzimek and Grzimek, 1960 [33]; Bartholomew and Pennycuick, 1973 [20]; Melack, 1978 [34]). These censuses have been sporadic and at times conducted at individual sites (Mlingwa and Baker, 2006 [12]). The attempts to estimate flamingo populations through aerial survey in Tanzania were first made by Grzimek and Grzimek (1960) [33] who counted the birds and nests at lake Natron. Despite the sporadic nature of the previously conducted census, the available data indicate the nomadic nature of this species within the soda lakes of east African region. The results from casual observations as well as a number of aerial counts and censuses suggest that east Africa frequently holds a significant proportion of the total world population of Lesser Flamingos (Tuite, 2000 [35]).

In east African alkaline saline lakes, various authors have reported different estimates of the population numbers of the Lesser Flamingo. For example, Tuite (1978 and 1979) [7] [36] observed that the total number of Lesser Flamingo counted in Kenyan and Northern Tanzanian soda lakes varied from 430,000 to 540,000. While Mlingwa and Baker (2006) [12] reported variations in the species numbers in northern Tanzania soda lakes, where their data indicates that the lowest number of birds recorded was 68,163 in 1969, and the highest was 2,759,026 in 1995. Moreover, Bartholomew and Pennycuick (1973) [20], during March 1969 survey which included most of the lakes in the eastern Rift valley, produced a total population estimate of about 1,000,000 birds. During 1972, 1973 and 1974, the aerial photographic surveys by Vareschi, which only included lake Bogoria and Nakuru, produced estimates of between 1,000,000 and 1,400,000 birds (Vareschi, 1978 [6]). Surveys conducted in the 1950's indicated that outside the breeding periods, lake Bogoria and lake Nakuru frequently support large concentrations of Lesser Flamingo, often numbering several hundred thousand and sometimes more than a million (Tuite, 1979 [36]).

In recent decades, there have been changes in the ecohydrological health of lake Manyara ecosystem caused by increased water abstraction for irrigation, tourism developments, degradation of catchment forests and increased siltation due to unsustainable and poor land use practices (Kihwele and Moronda, 2004 [13], Nonga, 2010 [28]). In addition, increased population growth, expansion and development for new agricultural land in the surrounding areas pose a great threat to the lake's water quality due to increased use of inorganic fertilizers, insecticides and pesticides (Nonga, 2011 [14]). Since lake Manyara is the low point of the basin, it acts as a sink for various pollutants coming from increased agricultural and tourism activities. These pollutants result in eutrophication of the lake posing a threat to natural aquatic ecosystem and contributing to environmental damage and ecological changes (Yanda and Madulu, 2005 [37]). This occurs as a result of the interaction between the lake and the up-stream land users that lead to nutrient enrichment of the lake (UNEP, 2005 [38]). The chemicals in turn affect the biota of the lake, particularly the phytoplankton. Changes in phytoplankton community may affect Lesser Flamingo numbers and distribution patterns. The ecological health of lake Manyara sub-ecosystem is dynamic and constantly changing with seasons and the climate variability of the area.

Little is known on seasonal abundance of the Lesser Flamingo numbers in east African saline Lakes in relation to the abundance of phytoplankton, their food source. While it is critically important to carry out the census studies, information on the temporal Lesser Flamingo population size and trends in lake Manyara is needed in order to relate the biological, physiological and chemical status of the lake with population size and trends of this bird species. Therefore this study intended to assess temporal population size of the Lesser Flamingo in the lake in order to provide information that can be used to relate population trends for long term monitoring programme. Of all the known Lesser Flamingo population counts and censuses conducted, non among them has tried to estimate monthly fluctuation in the abundance of the Lesser Flamingo in lake Manyara. Therefore it is critical to document the monthly ecohydrological dynamics of lake Manyara and assess its influence on the sea- 
sonal abundance of the Lesser Flamingo, the primary consumer of phytoplankton.

Temporal variations in the abundance of Lesser Flamingo may indicate changes in the importance of each of the soda lakes to these bird species both within a year and between years (Mlingwa and Baker, 2006 [12]). These variations may be attributed to changes in the water quality and quantity that are important for ensuring and sustaining food supply for these water birds. For lake Manyara in particular, the seasonal variation in phytoplankton composition and abundance in relation to Lesser Flamingo abundance have had little attention from researchers despite the fact that Lesser Flamingo is threatened by habitat degradation and pollution (Mlingwa and Baker, 2006 [12]). Therefore it was important to establish if there is a relationship between limnological parameters and the abundance of Lesser Flamingo in lake Manyara. There is substantial understanding on the main food sources for the Lesser Flamingo in alkaline saline lakes of east Africa, but little is known on the seasonal abundance and diversity of phytoplankton in relation to the abiotic factors in lake Manyara.

\section{Materials and Methods}

\subsection{Study Area}

Lake Manyara, where this study was conducted is located in Manyara region, in the northern part of Tanzania. The lake covers an area of about $520 \mathrm{~km}^{2}$. It is about $40 \mathrm{~km}$ long and $13 \mathrm{~km}$ wide (Figure 1) with a shallow depth of about $2 \mathrm{~m}$ at highest water level during extremely wet years. The livelihood of lake Manyara is highly depended on rainfall upstream that feeds the rivers and streams originating from the highlands of Ngorongoro, Karatu and Mbulu._The drainage of the lake is a closed system with about eight rivers (Simba, Magara, Endalla, Dagaa, Bagayo, Endabash, Mikindu and Iyambi) discharging its water into it. About $44 \%$ of the total area of the lake (i.e., $230 \mathrm{~km}^{2}$ ) falls within the lake Manyara National Park. The main sources of water for the lake are precipitation and surface run-off. The climate of the area is semi-arid with a bimodal rainfall patterns (annual rainfall ranging between $400-600 \mathrm{~mm}$ ). The short rains occur between October and December and the long rains between February and May (TANAPA, 2002 [39]).

Three sites, Jangwani (36 M 0816285, UTM 9620907) site one, Endala (36 M 0810382, UTM 9614841) site

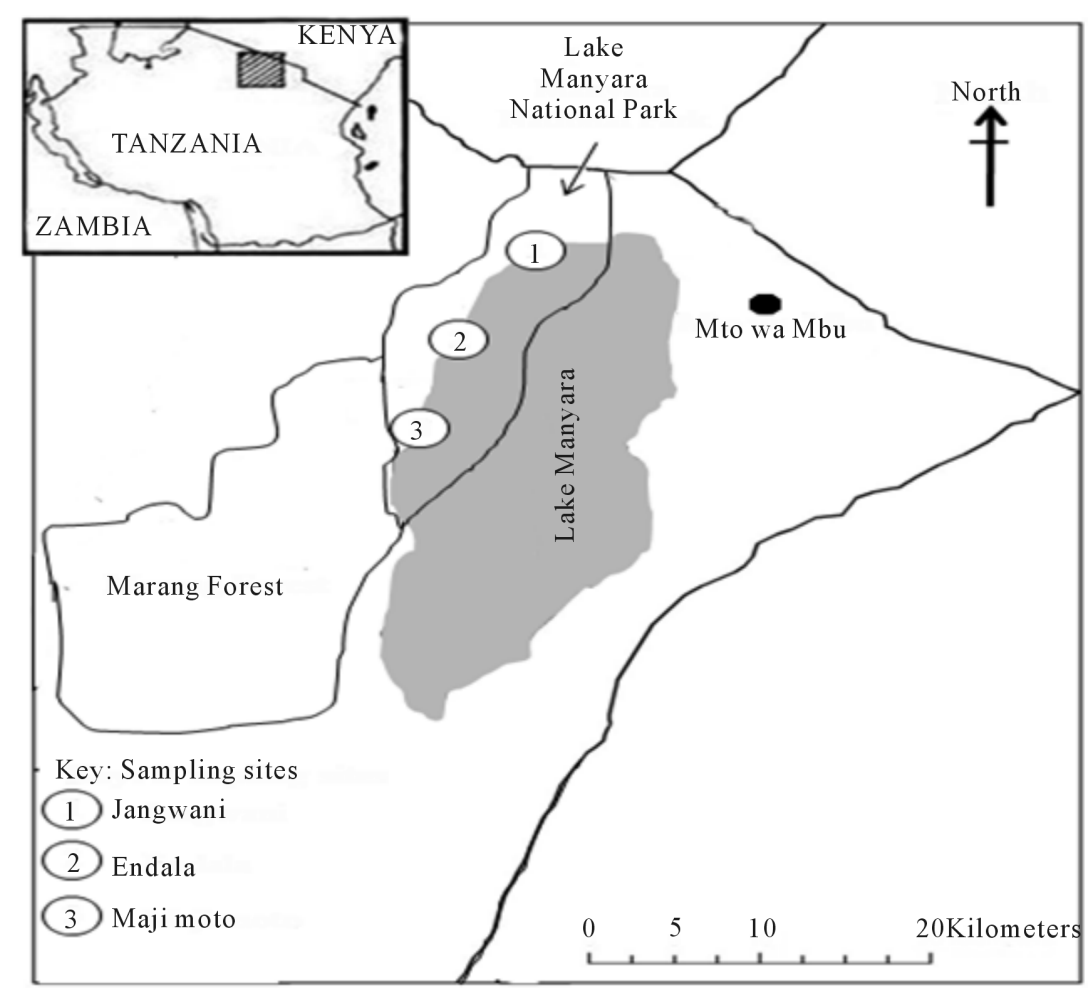

Figure 1. Map Showing the Locations of Lake Manyara National Park and Sampling Sites for Phytoplankton Abundance, Diversity and Limnological Parameters. 
two and Maji Moto (36 M 0804887, UTM 9598155) site three were selected as sampling sites/stations for the phytoplankton diversity and abundance as well as other limnological parameters (Figure 1). The sites were systematically selected in order to determine the effect of fresh water from rivers and hot springs on the water quality and phytoplankton abundance and diversity of the lake. Site one is located at the mouth of Simba river and therefore its limnological characteristics assumed to be influenced by fresh water draining the lake. Site two is located in an area away from the influence of a fresh water from the river and water from the hot springs while site three was located where hot springs drain its waters into the lake and therefore assumed to have influence on the limnological characteristics of this site.

To assess the abundance of Lesser Flamingo, a census was carried out on a monthly basis by conducting ground surveys on the eastern and western sides of the lake, whereby the Lesser Flamingo were counted on each visit. Observers stopped at every vantage point with flocks of flamingo to do the counting (Figure 2 and Table 1). This study was conducted from July 2007 to August 2008. The period from June to September 2007 and January through February 2008 was considered as a dry_season while the period from October to December

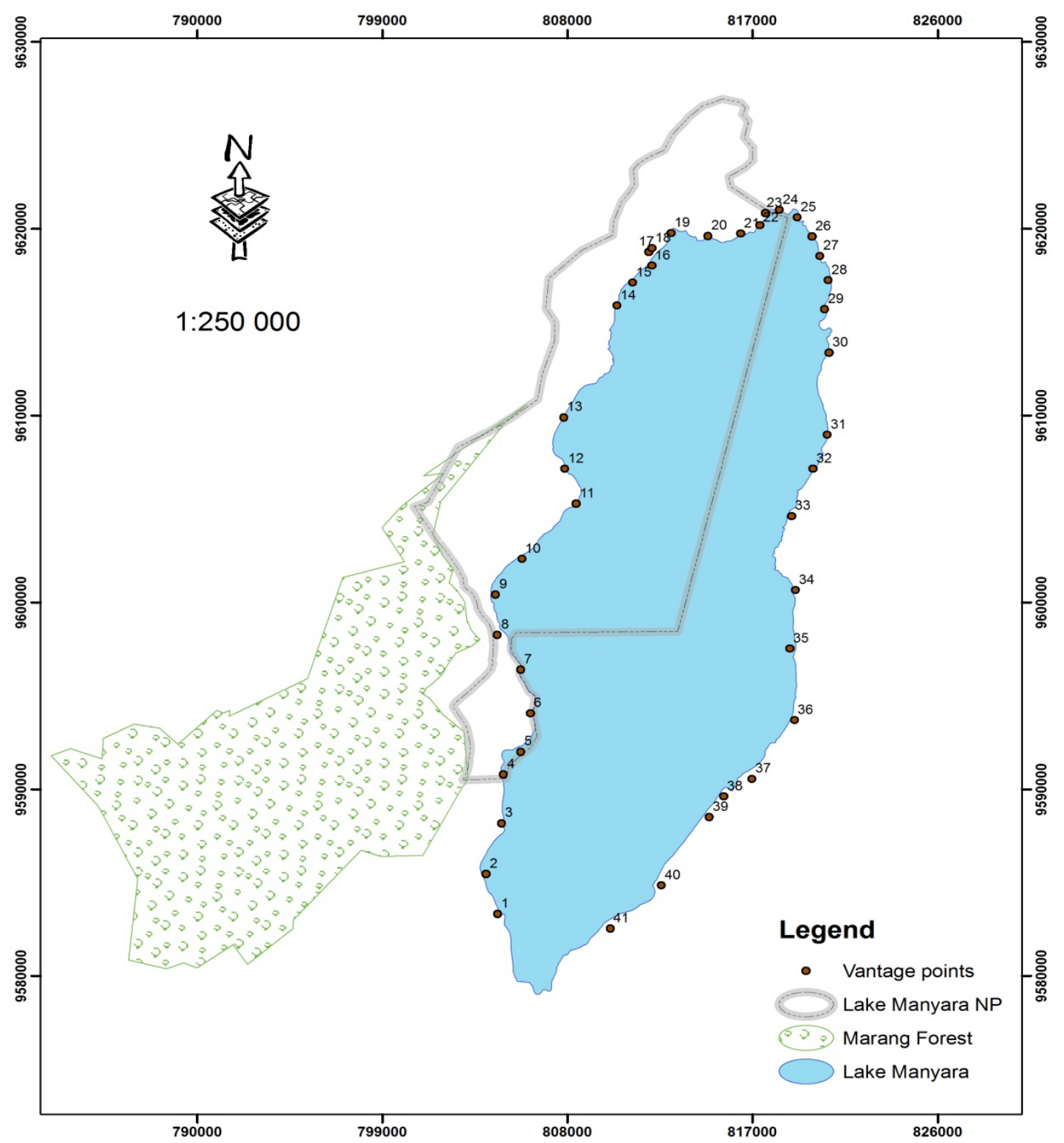

Figure 2. Map of lake Manyara showing counting points (vantage points) for Lesser Flamingo during the study period. 
Table 1. Geographical Positioning System (GPS) coordinates for Lesser Flamingo counting Stations/vantage points based on UTM system.

\begin{tabular}{|c|c|c|c|c|c|}
\hline \multicolumn{3}{|c|}{ Coordinates (Eastern side) } & \multicolumn{3}{|c|}{ Coordinates (Western side) } \\
\hline Vantage Points & Eastings & Northings & Vantage Points & Eastings & Northings \\
\hline 1 & 804604 & 9583307 & 23 & 817638 & 9620849 \\
\hline 2 & 804043 & 9585457 & 24 & 818312 & 9621018 \\
\hline 3 & 804791 & 9588169 & 25 & 819175 & 9620618 \\
\hline 4 & 804884 & 9590787 & 26 & 819892 & 9619606 \\
\hline 5 & 805726 & 9592002 & 27 & 820271 & 9618553 \\
\hline 6 & 806193 & 9594059 & 28 & 820686 & 96117247 \\
\hline 7 & 805726 & 9596396 & 29 & 820502 & 9615710 \\
\hline 8 & 804597 & 9598266 & 30 & 820713 & 9613372 \\
\hline 9 & 804510 & 9600417 & 31 & 820629 & 9608969 \\
\hline 10 & 805788 & 9602329 & 32 & 819938 & 9607149 \\
\hline 11 & 808423 & 9605283 & 33 & 818909 & 9604624 \\
\hline 12 & 807864 & 9607158 & 34 & 819091 & 9600653 \\
\hline 13 & 810420 & 9609916 & 35 & 818816 & 9597518 \\
\hline 14 & 810404 & 9615897 & 36 & 819039 & 9593688 \\
\hline 15 & 811176 & 9617129 & 37 & 816982 & 9590544 \\
\hline 16 & 812096 & 9618031 & 38 & 815608 & 9589602 \\
\hline 17 & 811950 & 9618767 & 39 & 814898 & 9588500 \\
\hline 18 & 812099 & 9618971 & 40 & 812577 & 9584832 \\
\hline 19 & 813038 & 9619776 & 41 & 810085 & 9582528 \\
\hline 20 & 814836 & 9619628 & & & \\
\hline 21 & 816416 & 9619754 & & & \\
\hline 22 & 817364 & 9620196 & & & \\
\hline
\end{tabular}

2007 and March to May 2008 was regarded as a wet season.

\subsection{Flamingo Census}

Lesser Flamingo population densities were obtained through monthly ground counts during the study period. During May 2007, prior to the commencement of censuring exercise, counting/vantage points were established on the lake shoreline (Figure 2). Also it was during May 2007 when observers were trained on counting method for Lesser Flamingo. The counting exercise commenced during July 2007 and was carried out by six to eight observers whom were divided into two teams of three to four each. The teams simultaneously counted the birds starting from the eastern and western sides of the lake from the north east and north west to the south east and south west, respectively. During the counting exercise, observers stopped at established vantage point based on the abundance and distribution of Lesser Flamingo to divide the shore of the lake up into recognizable counting sections with flocks of Lesser Flamingos. Each observer from the teams independently, recorded the numbers of birds by counting 100 to 1000 and estimating the numbers of 100 or 1000 subgroups in the flock using binoculars $(10 \times 50)$ and telescope $(20 \times-60 \times 80 \mathrm{~mm})$. The number of birds at every vantage point was obtained as the mean value from the observers If only their individual counts differed by less than $10 \%$ from one observer to the other in the team. And when the individual counts varied by more than $10 \%$ from one observer to the other, the counting exercise was repeated by all observers in the group. The mean counts from vantage points were recorded and at the end of the day the total number of Lesser Flamingo was obtained as the total sum of the 
mean values obtained from all vantage points.

\subsection{Physicochemical Parameters}

Water temperature, $\mathrm{pH}$, turbidity, salinity, electrical conductivity and dissolved oxygen were measured in situ using a portable water quality checker (Horiba Model U-10, manufactured by Horiba group, Japan). Water transparency was also measured in situ using a $20 \mathrm{~cm}$ diameter Secchi disc, while water depths at the sampling points were measured using a tape measure.

\subsection{Determination of Inorganic Nutrient Concentration}

Water samples for determination of inorganic nutrients, and phytoplankton biomass were collected from the surface, stored in a $50 \mathrm{ml}$ plastic bottles and transported to the laboratory for analysis. Water samples for inorganic nutrient determination were collected from the water surface and immediately filtered through Millex-GS Millipore filter membrane of $0.45 \mu \mathrm{m}$ pore size. Filtered water samples were then stored in cool boxes at $4^{\circ} \mathrm{C}$ and transported to the University of Dar Es Salaam, Department of Aquatic Science and Fisheries laboratory at Kunduchi for further analysis. In the laboratory, the concentrations of the inorganic nutrients (need to mention the analyzed nutrients i.e. nitrate, nitrite, ammonium and phosphate) were determined using UV-spectrophotometer with a $1 \mathrm{~cm}$ cuvette following the APHA, (2005) [40] procedures. Nutrient concentrations were then calculated using a general linear equation as shown below:

$$
C_{(\mu \mathrm{g} / \mathrm{I})}=\frac{A \times f}{s}
$$

$C=$ Concentration of inorganic nutrients in micro gram per litre

$A=$ Measured absorbance in water sample (in absorbance unit)

$f=$ Factor from linear regression

$s=$ Thickness of cuvette (in $\mathrm{cm}$ )

\subsection{Phytoplankton Species Composition}

A 20- $\mu \mathrm{m}$ mesh sized plankton net was used to concentrate phytoplankton samples for qualitative analysis. The net was lowered to the bottom of the lake and hauled vertically so as to capture different microalgae in the water column. The samples were then kept in $50 \mathrm{ml}$ dark glass bottles and preserved using formalin to a final concentration of $4 \%$. In the laboratory, microalgae identification was done using a light microscope following the morphological descriptions given by Desikachary (1959) [41], Prescot (1978) [42], Anagnostidis and Komárek (1985, 1988) [43] [44], Komárek and Anagnostidis (1986) [45], and Hasle and Syversten (1997) [46].

\subsection{Phytoplankton Abundance}

To assess phytoplankton numerical abundance, water samples were collected using a Van Dom water sampler. The samples were kept in $50 \mathrm{ml}$ dark glass bottles and fixed using $0.5 \%$ lugol's solution and formalin was added to a final concentration of $2 \%$. All samples for phytoplankton analysis were stored in a dark box and transported to the laboratory. In the laboratory, phytoplankton cells and filaments were counted using a Sedgewick Rafter cell. Cells and filaments were counted to a confidence limit of $90 \%$ (i.e., at least 400 cells and/or filaments as described by Andersen and Throndsen (2003) [47]. However, for the month of February, the water sample from site three had a high level of suspended silt and this limited microscopic phytoplankton analysis in the laboratory.

\section{Results}

\subsection{Flamingo Abundance}

Generally, the numbers of the Lesser Flamingo showed a linear increase during the study period (Figure 3). The lowest number of Lesser Flamingo was 9319 individuals during August 2007 and the maximum number was 640,850 during August 2008. It was also in August 2008 that Lesser Flamingo deaths were observed at lake Manyara National Park (Figure 4). The numbers of Flamingo drastically rose-up from 35,206 individuals during 


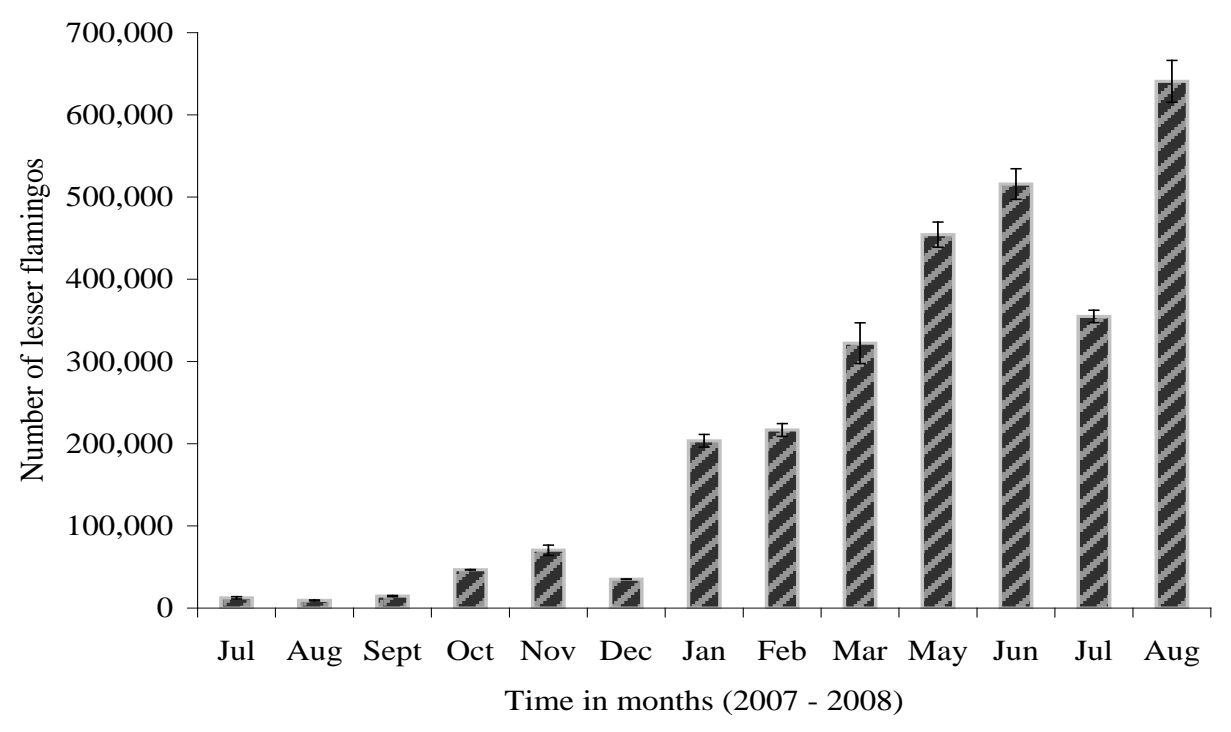

Figure 3. Temporal variations in the Lesser Flamingo abundance in lake Manyara.

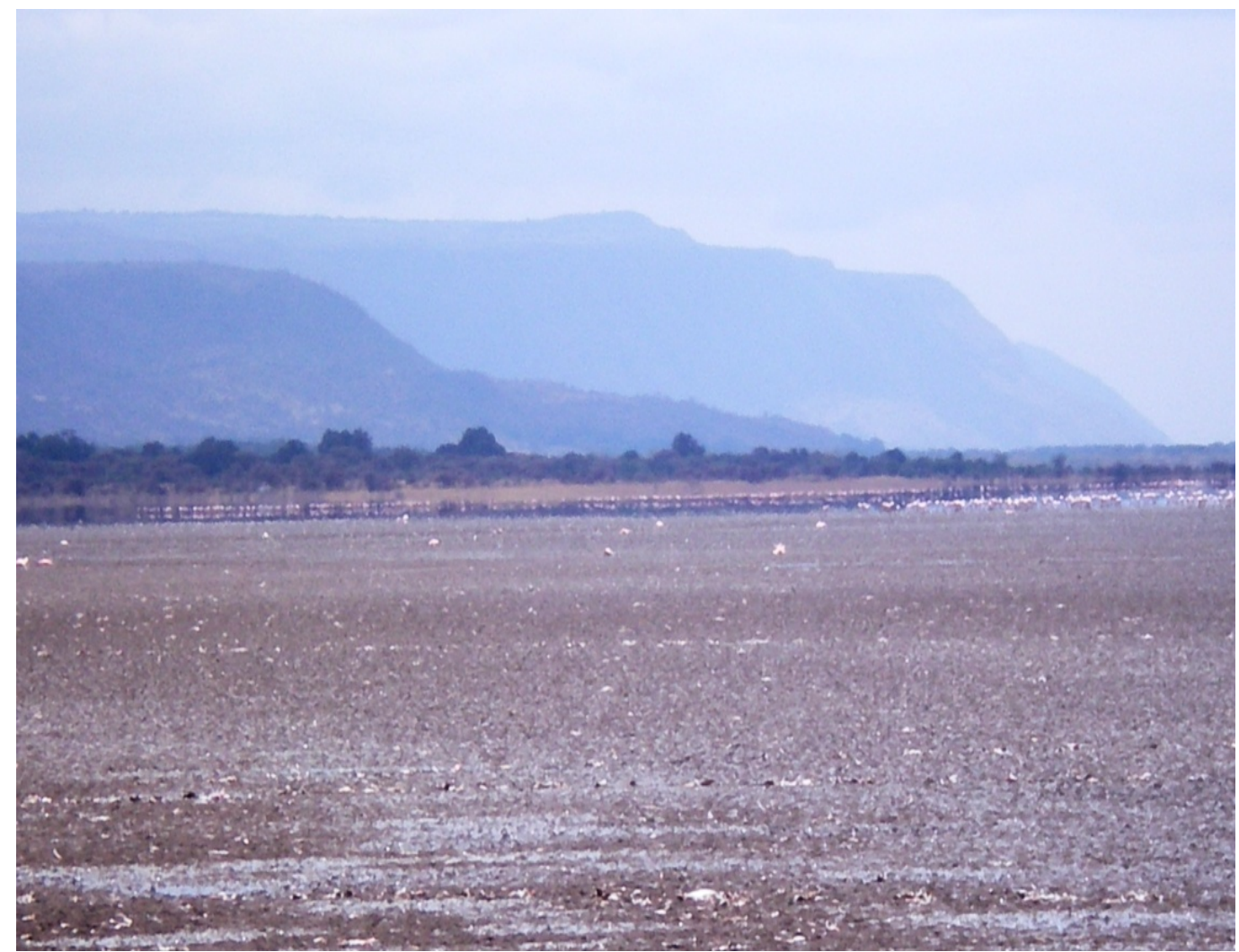

Figure 4. Carcasses of Lesser Flamingo as observed at Endalla in August 2008.

December 2007 to 203,577 in January 2008 and showed a gradual progressive increase to 515,777 during May 2008. Thereafter the population number dropped significantly to 354,834 individuals during June 2008 and thence followed by a sharp increase to a maximum number in August 2008. The large numbers of the Lesser Flamingo coincided with the large numbers of the cyanobacterium, Arthrospira fusiformis which dominated the water column of the lake during January - August 2008. Moreover, large numbers of the birds were observed inside the park, between vantage points 4 - 23 as compared to outside the park, probably as a result of disturbances 
from human activities such as fishing and livestock grazing taking place along the shore of the lake outside the park system. Pearson correlation analysis showed strong positive correlation between the lesser flamingo numbers with the concentration of nitrate (Figure 5), nitrite and ammonium $(r=0.948, p<0.001$ ) and between the number of lesser flamingo and the number of cyanobacterium Arthrospira sp (Figure 6) $(r=0.0855, \mathrm{p}<0.001)$.

\subsection{Phytoplankton Abundance}

Generally, the abundance of phytoplankton species fluctuated considerably and showed clear monthly variations within and among the study sites (Table 2). During the study period, Anabaena sp. was the most dominant among the phytoplankton species obtained in the lake (Table 3). A shift in the dominance of Anabaena sp. towards the dominance of Arthrospira sp was observed during March to August 2008. Cellular phytoplankton abundance ranged from the minimum value of 0 cells/ml (Cryptomonas sp.) at site one to the maximum value of 51024 cells/ml of Euglenophyte at site two (Table 4). While filamentous phytoplankton abundance ranged from the minimum value of 0 filaments $/ \mathrm{ml}$ of Ankistrodesmus $s p$ at site two to the maximum value of 153744 of Anabaena sp. at site three (Table 3). However, total monthly phytoplankton abundance ranged from 95 cells and filaments/ml observed during February 2008 at Site three, to 71192 cells and filaments/ml observed during December 2007 at site two (Table 4). Arthrospira abundance showed significant positive correlation with ammonium, phosphate, nitrate, and nitrite $(r=0.767, p=0.002 ; r=0.617, p=0.025 ; r=0.863, p=0.0001 ; r=0.661$, $\mathrm{p}=0.014$, respectively).

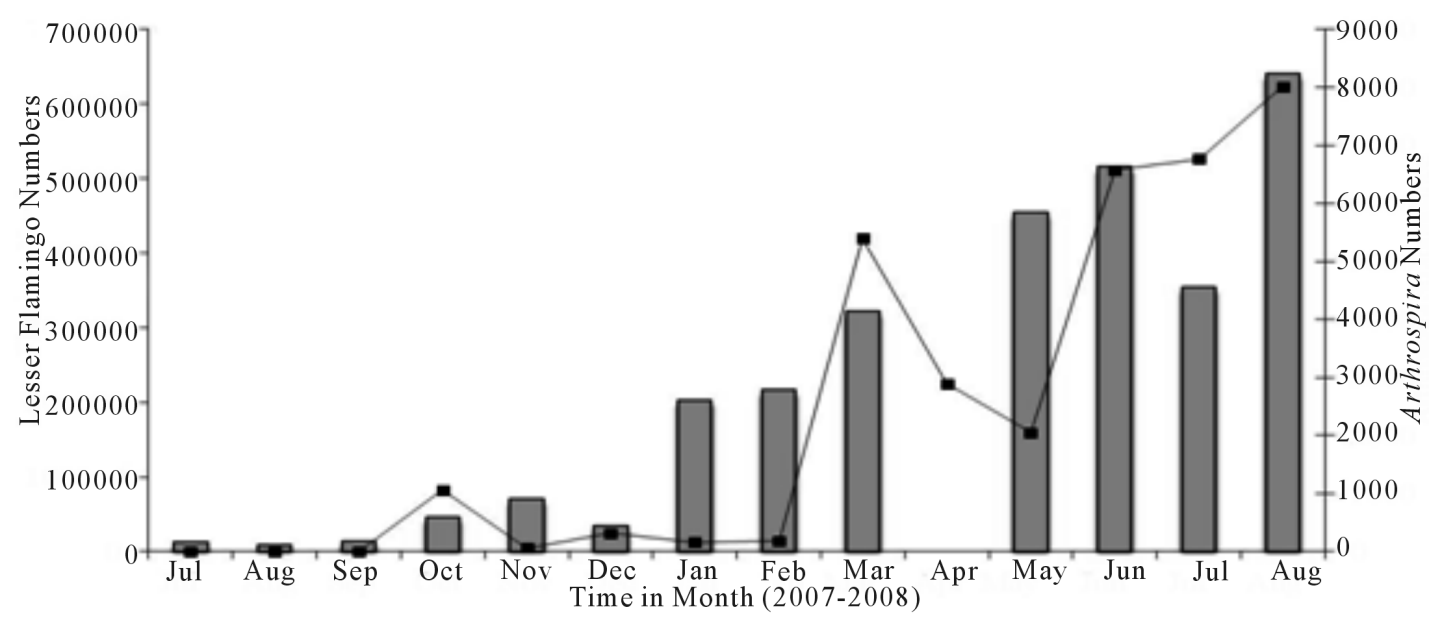

Figure 5. Relationship between the Lesser Flamingo numbers and the abundance of Arthrospira sp in lake Manyara.

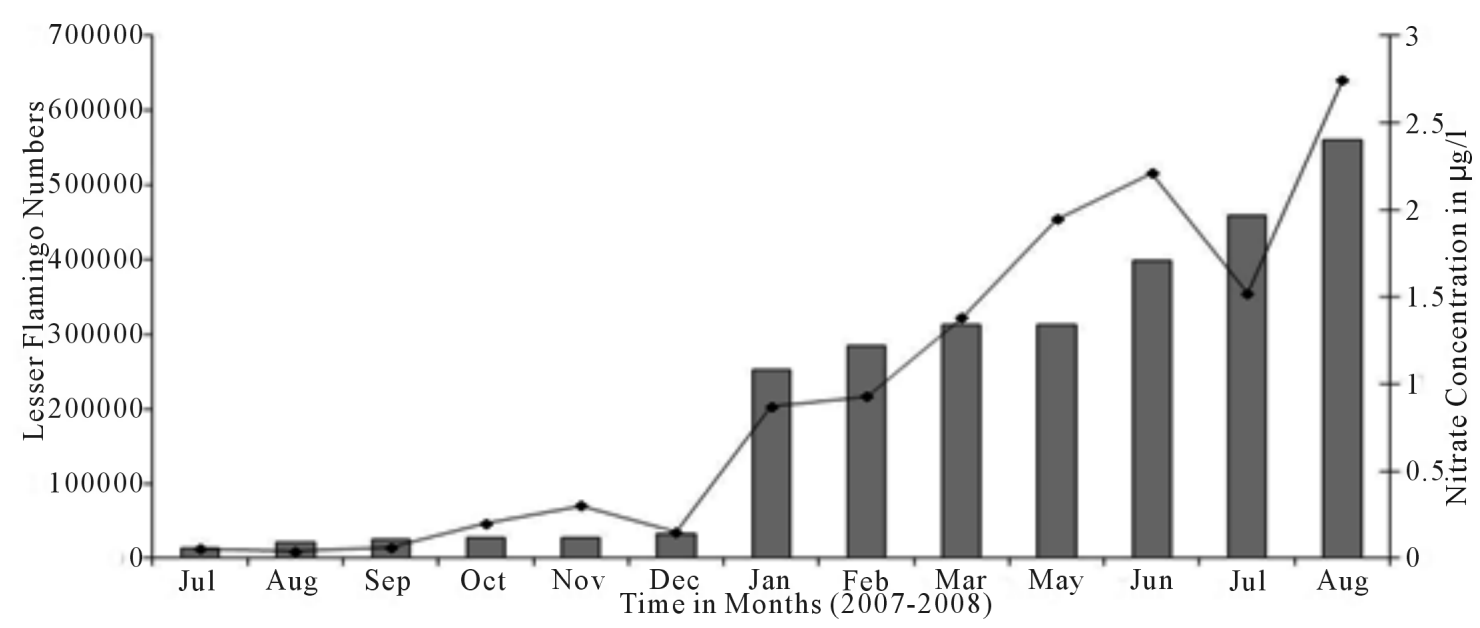

Figure 6. Relationship between the Lesser Flamingo numbers and nitrate concentration in lake Manyara. 
Table 2. Monthly phytoplankton abundance counted during the study period.

\begin{tabular}{ccccc}
\hline \multirow{2}{*}{ Month } & \multicolumn{3}{c}{ Phytoplankton abundance expressed as cells or filaments/ml } \\
\cline { 2 - 5 } July & Site one & Site two & Site three & Total/month \\
August & 2862 & 15,200 & 2662 & $\mathbf{2 0 , 7 2 4}$ \\
September & 13,457 & 22,935 & 5025 & $\mathbf{4 1 , 4 1 7}$ \\
October & 45,649 & 19,733 & 64,494 & $\mathbf{1 2 9 , 8 7 6}$ \\
November & 23,008 & 19,858 & 15,180 & $\mathbf{5 8 , 0 4 6}$ \\
December & 2782 & 4256 & 19,186 & $\mathbf{2 6 , 2 2 4}$ \\
January & 5813 & 71,192 & 12,856 & $\mathbf{8 9 , 8 6 1}$ \\
February & 6636 & & 275 & $\mathbf{6 9 1 1}$ \\
March & 1278 & & 95 & $\mathbf{1 3 7 3}$ \\
April & 1736 & 6415 & 13,262 & $\mathbf{2 1 , 4 1 3}$ \\
May & 1605 & 9115 & 3399 & $\mathbf{1 4 , 1 1 9}$ \\
June & 2255 & 6651 & 13,451 & $\mathbf{2 2 , 3 5 7}$ \\
July & 1446 & 16,292 & 22,063 & $\mathbf{3 9 , 8 0 1}$ \\
August & 1684 & 14,732 & 25,646 & $\mathbf{4 2 , 0 6 2}$ \\
Total/site & 2426 & 22,836 & 24,122 & $\mathbf{4 9 , 3 8 4}$ \\
\hline
\end{tabular}

Table 3. Comparative table of filamentous phytoplankton species abundance counted during the study.

\begin{tabular}{ccccc}
\hline \multirow{2}{*}{ Species } & \multicolumn{4}{c}{ Phytoplankton abundance expressed as cells or filaments/ml } \\
\cline { 2 - 5 } & Site one & Site two & Site three & Total/sp \\
\hline Arthrospira sp & 5376 & 39927 & 55243 & $\mathbf{1 0 0 5 4 6}$ \\
Anabaena sp & 79403 & 108650 & 153744 & $\mathbf{3 4 1 7 9 7}$ \\
Nostoc sp & 16 & 460 & 572 & $\mathbf{1 0 4 8}$ \\
Chlorogonium sp & 454 & 106 & 14 & $\mathbf{5 7 4}$ \\
Ankistrodesmua sp & 4952 & 0 & 540 & $\mathbf{5 4 9 2}$ \\
Oscilatoria sp & 555 & 373 & 655 & $\mathbf{1 5 8 3}$ \\
Spirulina $s p$ & 5260 & 18392 & 69 & $\mathbf{2 3 7 2 1}$ \\
Phormidium $s p$ & 1487 & 251 & 960 & $\mathbf{2 6 9 8}$ \\
Total/site & $\mathbf{9 7 5 0 3}$ & $\mathbf{1 6 8 1 5 9}$ & $\mathbf{2 1 1 7 9 7}$ & $\mathbf{4 7 7 4 5 9}$ \\
\hline
\end{tabular}

\section{Discussion}

The observed gradual increase in the number of Lesser Flamingo at lake Manyara could be due to increased in the quantity and quality of the preferred food species as various authors (Vareschi, 1978 [6]; Tuite, 1978 [7]; Naswira, 2000 [48]; Harper et al, 2003 [30]; Childress et al, 2008 [49]; Krienitz and Kotut, 2010 [9] and Kaggwa et al, 2013 [50]) reported, the cyanobacterium Arthrospira fusiformis to account for large number of Lesser Flamingo. For example, a study by Childress et al. (2008) [49] reported that Lesser Flamingo are adapted to respond to changes in the environmental conditions such as availability of food and water by moving among wetlands and therefore depend on a network of suitable sites. Pearson correlation analysis showed a significant positive correlation between the abundance of Arthrospira sp and Lesser Flamingo population during the current study. The reason for this could possibly be related to the increase in the abundance of cyanobacterium, Arthrospira $s p$ which is said to be the preferred food source of the Lesser Flamingo (Vareschi, 1982 [51]; Tuite, 
Table 4. Comparative table of cellular phytoplankton species abundance counted during the study

\begin{tabular}{ccccc}
\hline \multirow{2}{*}{ Species } & \multicolumn{3}{c}{ Phytoplankton abundance expressed as cells or filaments/ml } \\
\cline { 2 - 5 } & Site one & Site two & Site three & Total/sp \\
\hline Microcytis sp & 2317 & 1613 & 2113 & $\mathbf{6 0 4 3}$ \\
Chrolophyte & 1875 & 138 & 2040 & $\mathbf{4 0 5 3}$ \\
Aphanocapsa sp & 147 & 600 & 594 & $\mathbf{1 3 4 1}$ \\
Navicula sp & 6005 & 7006 & 2248 & $\mathbf{1 5 2 5 9}$ \\
Euglenophyte & 676 & 51024 & 1475 & $\mathbf{5 3 1 7 5}$ \\
Synechoccocus sp & 68 & 167 & 986 & $\mathbf{1 2 2 1}$ \\
Bacillariophyte & 116 & 278 & 305 & $\mathbf{6 9 9}$ \\
Cryptomonas sp & 0 & 61 & 9 & $\mathbf{7 0}$ \\
Cylindrospermum sp & 383 & 169 & 149 & $\mathbf{7 0 1}$ \\
Spirogira sp & 685 & 0 & 0 & $\mathbf{6 8 5}$ \\
Total/site & $\mathbf{1 2 2 7 2}$ & $\mathbf{6 1 0 5 6}$ & $\mathbf{9 9 1 9}$ & $\mathbf{8 3 2 4 7}$
\end{tabular}

2000 [35]; Ballot et al., 2005 [52]). On contrary, at low abundance of Arthrospira sp, the Lesser Flamingo resorted to eating benthic microalgae thereby maintaining a dispersed distribution over the lake. This is in conformity with Tuite (2000) [35] who also reported two distinct patterns of Lesser Flamingo population distribution in east African saline lakes; clumped and dispersed. Clumped population distribution occurred only when there was a bloom of Arthrospira fusiformis. When Arthrospira densities fell below optimum level (thresholds), Lesser Flamingo could not obtain enough food to meet their energy requirements. Thus Lesser Flamingo were forced to change their diet to benthic microalgae thereby adopting dispersed distributions (Tuite, 2000 [35]).

Alternatively, the changes in the abundance of the food quality and quantity for Lesser Flamingo is however further affecting the distribution of this bird species in lake Manyara as some of the microalgae are said to be too small to meet the size requirements of highly specialized bills of the Lesser Flamingos (Krienitz, et al., 2013 [53]). As the case, during certain months of the study, the concentration of Arthrospira sp abundance was low and could have not been sufficient to support large numbers of Lesser Flamingo in lake Manyara. This is in agreement withKrienitz and Kotut, (2010) [9] whom during March 2004 recorded the concentration of Arthrospira of $44 \mathrm{mg} \cdot \mathrm{L}^{-1}$ that was also not sufficient to feed the higher number of Lesser Flamingos in lake Nakuru. This is because an adult Lesser Flamingo require a daily supply of about $70 \mathrm{~g} \cdot \mathrm{d}^{-1}$ dry mass of Arthrospira (Vareschi, 1978 [6]). Therefore in order to supply adequate quality and quantity of food to the primary consumers, the Lesser Flamingo, while maintaining the balance between members of the food chain, lake Manyara subecosystem has to provide thresholds that are pre-requisite for microalgae development.

The significant negative correlation between the abundance of Anabaena sp. and that of the Lesser Flamingo numbers observed corroborates recent observation by Krienitz and Kotut, (2010) [9]. The authors reported that the Anabaenopsis sp block and clog the Lesser Flamingo food filtration system as they form mucilaginous slimy colonies. The observed significant positive correlation between the number of Lesser Flamingo and the concentration of ammonia, nitrate and nitrite in the water column is mostly likely to be due to the presence of high number of the Lesser Flamingo and other waterbirds as their droppings into water contributes to the nutrient enrichment.

The low Lesser Flamingo numbers recorded from July to December 2007 may possibly be caused by the migration of the birds to lake Natron for breeding since these species commence breeding around October and December (Brown and Root, 1971 [4]). The low number during this period may also be caused by the inadequate food supply in lake Manyara as depicted by low abundance of cyanobacteria with the genus Anabaena dominating the phytoplankton community. Another reason could be inaccessibility of food by the Lesser Flamingo due to high water level in the lake thereby limiting feeding success. The high water level affects feeding success since Lesser Flamingo are not specialized swimmers like the Anatids and Pelicanids but rather tend to filter feed while walking on the sediment substrate. This is evident from uneven abundances and distribution of Lesser Flamingos observed utilizing the lake during this study as large numbers of the birds were observed during pe- 
riods of very low water levels. When the water level was high, Lesser Flamingos were observed to be restricted to the lake shores but during periods low water they utilized the entire lake for feeding. My observation is in agreement with Romano et al. (2009) [54] who observed that fluctuations in the number of Lesser Flamingo were associated with inter-annual variation in rainfall that affected the lake depth, surface area and the physicochemical composition of the lowland wetlands.

It has been hypothesized that the Lesser Flamingo in East Africa alkaline lakes belongs to a single population and that frequent movements between different wetlands occur (Simmons, 2000 [25]). The seasonal and annual fluctuations in the Lesser Flamingo numbers within lake Manyara becomes a function of the available phytoplankton abundance that is also controlled by its physical and chemical characteristics. During the periods between February to August 2008, large numbers of Arthrospira dominated the phytoplankton assemblages, coincidentally with large numbers of Lesser Flamingo were observed. While during periods between July to December 2007, the cyanobacterium Anabaena showed slightly monospecific dominance, with low numbers of Lesser Flamingo indicating the lower food quality of other phytoplankton species (Kaggwa et al., 2013 [50]) as opposed by a very high nutritional value of Arthrospira (Tokuşoglu and üUnal 2003 [55]; Mühling et al., 2005 [56]; Zieliñska and Chojnacka, 2009 [57]).

The ultimate impacts of the changes in the physical and chemical composition are manifested in the abundance of the phytoplankton (food for the Lesser Flamingo) which were associated with the flamingo numbers. The significant drop in the number of Lesser Flamingo from 400,000 in August 1956 to approximately 3000 in April 1973 reported by Brown (1973) [21]. And the increase in the number of Flamingo from 10,000 in August 1973 to 50,000 in April 1974 in Momela lakes reported by (Tuite, 1979 [36]) were also associated with changes in the abundance of Arthrospira. When Arthrospira biomass falls below a certain threshold, Lesser Flamingos are not able to obtain enough food to meet their energy requirements (Kaggwa et al., 2013 [50]). As a result, they move to other lakes with a more favourable food base, alternatively they change their food to the less desirable phytoplankton species (Sileo et al., 1979 [58]; Tuite, 2000 [35]).

The temporal fluctuations observed during my study in lake Manyara are compared with other researchers, Tuite, (1979) [36] and Mlingwa and Baker, (2006) [12] who used aerial photographic methods on the same lake. My counts during the periods between August - September 2007 and January - February 2008 as well as August 2008 were 9319, 14,574, 203,577, 216,705 and 640,850 Lesser Flamingo respectively which are considerably higher than 48,265 during September 1974, 63,740 February 1975, 41,230 August 1975 and 71,400 January 1976 (Tuite, 1979 [36]). WhileMlingwa and Baker, (2006) [12] reported 1313 during March 1969, 1,940,000 in 1991, 78,320 in November 1994, >1,000,000 in January 1995, 8264 in January 2002 and 382,500 in February 2004. The reasons for this big discrepancies are either due to the difference in the method used and/or counting errors as the aerial photography reported to be of more accurate than the ground count (Grzimek and Grzimek, 1960 [33]).

The remoteness of alkaline saline lakes prevents them from being accessible and result to coverage limitations during ground surveys. In addition, the degree of angle of observation due to visual observation can contribute to counting errors. The errors of direct visual counts were argued byGrzimek and Grzimek, (1960) [33]; and Graham and Bell, (1969) [59] to be large when using ground survey technique. These errors were corrected and minimized during this study by reducing the visual angle from which the observer counts the birds through counting Lesser Flamingo at an estimated distance of about 300 meters from the nearest birds. This is because the longer the distance of the flock from the counting observation, the large the error of overestimating as the observer become confused with reflection and mirage. However, Harper et al (2003) [30] during their study, they observed similarity in Lesser Flamingo data from ground and aerial surveys. During my study in lake Manyara, it was not possible to undertake aerial survey to ascertain the reliability of my numbers due to lack of funds however, considerations were taken so as the current ground count during this study yield useful and reliable census data.

Environmental conditions such as drought and availability of fresh water affect Lesser Flamingo ecology in the saline alkaline lakes, because they are interactive and correlated in different ways amongst themselves and with flamingo numbers (Raini and Ngowe, 2009 [60]). Therefore the temporal fluctuations in abundance of Lesser Flamingo observed during this study are likely due to be influenced by the water level which is expected to be adversely impacted by the climate change. Global mean temperatures has risen by $0.740 \mathrm{C}$ over the past century and the warming rate has doubled for the past 50 years (Madaka, 2007 [61]) while precipitation in Africa is simulated to increase by 2050 (Hudson and Jones, 2002 [62]). All these changes are likely to affect aquatic 
systems in complex ways (Lovejoy and Hannah, 2005 [63]). The climate change impacts are likely to devastative to alkaline saline lakes and their biota as a result of being found in arid and same arid environments.

The current study observed a shift in the phytoplankton species abundance and dominance during the period February 2008 suggesting that the Lesser Flamingo may be feeding on different phytoplankton species. These changes in the feeding pattern of the Lesser Flamingo are likely associated with the observed shift and changes in phytoplankton species composition and abundances. However, the accessibility and abundances of microalgae probably influenced Lesser Flamingo numbers and distribution. This is in agreement with the work of other authors (Rich, 1932 [64]; Jenkins, 1957 [65] and Tuite, 1978 [7]), who reported that the diet of the Lesser Flamingo consists almost entirely of planktonic filamentous blue green algae and benthic diatoms. Tuite (2000) [35] observed that the variability in occurrence of Spirulina blooms in different Rift valley lakes in east Africa also appeared to have impact to the Lesser Flamingo numbers and distribution as the cyanobacterium Arthrospira fusiformis blooms and then disappear.

Lesser Flamingo are filter feeders feeding on phytoplankton species inhabiting the waters of the wetlands. Lesser Flamingo feeds by walking on the sediment substrate while keeping pace from one another at an estimated observed distance of between 0.5 to 1 from conspecifics. This suggests that such a distance has to be maintained between the bird to ensure that enough area is available for the Lesser Flamingo to feed on the algae. However, the magnitude of the distances is probably assumed, likely to be influenced by the abundances and accessibility of the phytoplankton.

The distribution of Lesser Flamingo within the lake varied on a monthly and sometimes on a daily basis. This distribution could possibly be caused by variations in the phytoplankton species composition and abundance within and between alkaline saline lakes. As the case for lake Manyara, phytoplankton species composition and abundance is a major driver to the distribution of the Lesser Flamingo which shows itinerant movements to find lakes with suitable conditions (Krienitz and Kotut, 2010 [9], Kaggwa et al, 2013 [50]). The physicochemical properties of the lake possibly have thresholds (optimality) that affected phytoplankton growth and development as influenced with the light illumination for photosynthesis and dissolved oxygen for respiration. These thresholds are likely to differ within and between lakes on spatial and temporal scales depending on the local ecological processes, environmental and climate variability of that particular lake system.

\section{Lesser Flamingo Deaths in Lake Manyara}

During this study, about 1000 deaths of the Lesser Flamingo were recorded from August to September 2008. However, the death toll could have been higher as no further carcases counts were made after September 2008. The carcasses of the Lesser Flamingo which were observed had no internal organs. This suggested that scavenging animals such as Marabou storks (Leptoptilos crumeniferus), Lappet-faced vultures (Torgos tracheliotos) and Jackals (Canis aureus) which do occur in lake Manyara National Park might have eaten them. The 2004 Flamingo deaths were associated with intoxication from cyanobacteria (Lugomela et al, 2006 [66]) and the current death can also be linked to intoxication as the moribund birds showed similar clinical signs as those observed during 2004. An interview with the park ecologist challenged the involvement of cyanobacterial toxins to the August 2008 Lesser Flamingo deaths as scavengers were preying on carcasses of Lesser Flamingo. Therefore, two possibilities are suggested; first, the deaths of the Lesser Flamingo were due to factors that were not lethal to scavengers. Secondly, if the cyanobacterial toxins were involved, it was at such low level that they could not kill the scavengers immediately.

The recent deaths cases were observed in Site one, Msasa, Endalla, Bagayo, Endabash and Maji Moto areas, similar areas where about 43,850 deaths had been encountered in July and August 2004 that also suggesting the possibility of the same causes of these deaths. The cause for the deaths observed during the study period has not been established. Further along, Similarly, Krienitz et al., (2003) [8] andBallot et al., (2004) [67] have detected high concentration of cyanotoxins (microcystins and anatoxin-a) from water sample in lake Nakuru following investigation towards the Lesser Flamingo deaths. The July to August 2004 Lesser Flamingo deaths in northern Tanzania soda lakes were also associated with intoxication from the cyanobacterium, Arthrospira fusiformis (Lugomela et al., 2006 [66]).

The involvement of the cyanobacterial toxins in the deaths of the Lesser Flamingo cannot be ignored but it can be associated with other factors such as energy loss while migrating and starvation. The occurrence of these deaths during the dry season and at large Lesser Flamingo numbers raise some questions. The first is whether 
the distances travelled by the migratory Lesser Flamingo might be very long, adversely stressing this species. Second, whether the deaths are due to internal factors, or external factors or a combination of both. Little data exist on the feeding pattern of Lesser Flamingo while migrating from one saline lake to the other between the different alkaline saline lakes of east Africa. Tuite (1981) [68] reported that the Lesser Flamingo deposit fat when feeding on blue green algae, Spirulina when in readiness for migration. Further along, this suggests that Lesser Flamingo depend on body fat as the source of energy during migration and therefore are subjected to starvation and stress as their feeding pattern during migration is not well understood. This situation makes Lesser Flamingo vulnerable and susceptible to even low levels of cyanotoxin toxicity.

In 2004, Lesser Flamingo deaths occurred when the lake had more than 1,500,000 birds (TANAPA, 2005 [17]). Also in 2008, deaths occurred when the population of flamingo in the lake was about 640,850 birds. In 2004, more than 40,000 birds died in lake Manyara while in 2008 about 1000 deaths were observed. The occurrence of these deaths during periods when the lake is inhabited by large numbers of Lesser Flamingo, suggest that toxins from cyanobacteria, even at low concentration levels in combination with stress and hunger could kill birds. My observation agrees with Krienitz and Kotut, (2010) [9] who recorded the lowest phytoplankton biomass of $12 \mathrm{mg} \cdot \mathrm{l}^{-1}$ in lake Nakuru during July 2006 and observed exhausted, underweight lesser flamingo feeding from the lake shore. During July 2008, two-thirds of the phytoplankton biomass in lake Bogoria observed by Krienitz and Kotut, (2010) [9] was due to Anabaenopsis sp coincidentally, the deaths of about 30,000 Lesser Flamingos occurred at the same time with the mass development of Anabaenopsis in July 2008. As the Anabaenopsis $s p$ is too large to be ingested by the Lesser Flamingo, resulting to starvation that might have contributed to the mass die-off observed at Lake Bogoria during July 2008. This could be the case for lake Manyara during August 2008, when Lesser Flamingo numbers reached a peak of 640,850. It resulted to increased grazing pressure on the Arthrospira by the bird species, resulting into a reduction in the biomass and consequently malnutrition and starvation to the Lesser Flamingo.

\section{Conclusions}

The fluctuations in the abundance of Lesser Flamingo from July 2007 to August 2008 are associated and linked to the changes in the phytoplankton species community which is influenced by fluctuations on the physicochemical characteristics of the lake. This is supported with strong positive correlation between the Lesser Flamingo abundance with the abundance of cyanobacterium, Arthrospira sp. The study suggests that water temperature, salinity and secchi disc readings regulate the temporal and spatial abundance and diversity of phytoplankton, their blooms, and the abundance and distribution of the Lesser Flamingo. However, the observed variations in the nutrients concentrations of the lake are suggested to be drivers for the phytoplankton diversity and abundance with ultimate influence on the numbers and distribution of the primary consumers, the Lesser Flamingo.

Despite Lesser Flamingo utilizing the lake in large numbers at times, recently, reported deaths of this species are of considerable conservation importance with a potential threat to the population size of the Lesser Flamingo. The 43,850 deaths reported in 2004 and 1000 deaths observed during the current study compounded with altered hydrology and degradation of habitats to the Lesser Flamingo pose a major threat to these waterbirds and are likely to be a future conservation challenge. The decrease in the population estimates from about 4 million birds in 1960s to about 2.5 million birds to date calls for immediate implementation of the National Single Species Action Plan (NSSAP) if sustainable conservation of Lesser Flamingos is to be achieved.

\section{Acknowledgements}

I am grateful to the Director General of TANAPA, and the Co-ordinator of ACM-UDSM as well as Prof. David Harper (Darwin Initiative Project Co-ordinator) for making funds available for this study. I am also grateful to the Department of Zoology and Wildlife Conservation, and the Department of Aquatic Science and Fisheries for providing laboratory space during my research activities.

\section{References}

[1] Brown, L.H., Urban, E.K. and Newman, K. (1982) The Birds of Africa. Volume 1. Academic Press Inc., London.

[2] Del Hoyo, J., Elliot, A. and Sargatal, J. (1992) Flamingos. Handbook of the Birds of the World, Volume 1. Lynx Editions, Barcelona, Ostrich to Ducks, 696. 
[3] Mundkur, T. (1997) The Lesser Flamingo. A Summary of Its Current Distribution and Conservation in Asia. In: Howard, G. Ed., Conservation of Lesser Flamingo in East Africa and Beyond. Proceedings of a Workshop at Lake Bogoria, Kenya, 26-29 August, 1997. IUCN Eastern Africa Regional Programme.

[4] Brown, L.H. and Root, A. (1971) The Breeding Behavior of the Lesser Flamingo Phoeniconaias minor. International Journal of Avian Science, 113, 147-172.

[5] Ndetei, R. and Muhandiki, V.S. (2005) Mortalities of Lesser Flamingos in Kenyan Rift Valley Saline Lakes and the Implications for Sustainable Management of the Lakes. Lakes and Reservoirs, Research and Management, 10, 51-58. http://dx.doi.org/10.1111/j.1440-1770.2005.00255.x

[6] Vareschi, E. (1978) The Ecology of Lake Nakuru (Kenya). I. Abundance and Feedingof the Lesser Flamingo. Oecologia, 32, 11-35. http://dx.doi.org/10.1007/BF00344687

[7] Tuite, C.H. (1978) The Lesser Flamingo (Phoeniconaias minor): Aspects of Its Ecology and Behaviour in the East African Rift Valley of Kenya and Northern Tanzania. Unpublished Ph. D. Thesis, University of Bristol, Bristol, UK.

[8] Krienitz, L., Ballot, A., Kotut, K., Wiegand, C., Putz, S., Metcalf, J.S., Coddm G.A. and Pflugmacher, S. (2003) Contribution of Hot Spring Cyanobacteria to the Mysterious Deaths of Lesser Flamingos at Lake Bogoria, Kenya. FEMS Microbiology Ecology, 43, 141-148. http://dx.doi.org/10.1111/j.1574-6941.2003.tb01053.x

[9] Krienitz, L. and Kotut, K. (2010) Fluctuating Algal Food Populations and the Occurrence of Lesser Flamingos (Phoeniconaias Minor) in Three Kenyan Rift Valley Lakes. Journal of Phycology, 46, 1088-1096. http://dx.doi.org/10.1111/j.1529-8817.2010.00915.x

[10] Melack, J.M. and Kilham, P. (1974) Photosynthetic Rates of Phytoplankton in East African Alkaline, Saline Lakes. Limnology and Oceanography, 19, 743-755.

[11] Owino, A.O., Bennun, L.A., Nasirwa, O. and Oyugi, J.O. (2002) Trends in Water Bird Numbers in the Southern Rift Valley of Kenya, 1991-2000. Waterbird Society, 25, 191-201.

[12] Mlingwa, C. and N. Baker. (2006) Lesser Flamingo Phoenicopterus minor Counts in Tanzanian Soda Lakes: Implications for Conservation. In: Boere, G.C., Galbraith, C.A. and Stroud, D.A. Eds., Waterbirds around the World. The Stationery Office, Edinburgh, 230-233.

[13] Kihwele, E.S. and Moronda, B.M. (2004) Assessment of Water Resources, Catchment Forests, River Management and Conservation in Manyara Basin. A report Submitted to TANAPA.

[14] Nonga, H.E., Mdegela, R.H., Lie, E., Sandvik, M. and Skaare, J.U. (2011) Assessment of Farming Practices and Uses of Agrochemicals in Lake Manyara basin, Tanzania. African Journal of Agricultural Research, 6, 2216-2230.

[15] Tebbs, E., Remedios, J., Avery, S. and Harper, D. (2011) Development of Remote Sensing Algorithms for Monitoring Biomass of Primary Producers in Alkaline-Saline Lakes from Planktonic and Benthic Sources. Remote Sensing and Geoinformation Not Only for Scientific Cooperation. Lena Halounová, Editor EARSeL.

[16] Acharya, G. (2000) Approaches to Valueing the Hidden Hydrological Services of Wetlands Ecosystems. Ecological Economics, 35, 63-74. http://dx.doi.org/10.1016/S0921-8009(00)00168-3

[17] TANAPA (2005) Ecological and Health Studies of Lesser Flamingos in Soda Lakes of Northern Tanzania. A Research Agenda to Establish the Current Deaths of Flamingos.

[18] IUCN (2004) Red List of Threatened Species. www.iucnredlist.org

[19] Wetlands International (2006) Waterbird Population Estimates. Fourth Edition, Wetlands International, Wageningen, The Netherlands.

[20] Bartholomew, G.A. and Pennycuick, C.J. (1973) The Flamingo and Pelican Populations of the Rift Valley Lakes in 1968-69. East African Wildlife Journal, 11, 189-198.

[21] Brown, L.H. (1973) The Mystery of the Flamingo. East African Publishing House, Nairobi.

[22] Nasirwa, O. (1994) Kenya Wetlands Working Group. Kenya Birds, 3, 53-54.

[23] Nasirwa, O. (1997) Status of Lesser Flamingo in Kenya. In: Howard, G. Ed., Conservation of Lesser Flamingo in East Africa and Beyond, IUCN Lake Bogoria, Nairobi, 22-24.

[24] Howard, G. (1997) Biology of the Lesser Flamingo. In: Howard, G. Ed., Conservation of Lesser Flamingo in East Africa and Beyond, Nairobi, 50-61. http://dx.doi.org/10.1023/A:1002977019700

[25] Simmons, R.E. (2000) Declines and Movements of Lesser Flamingo in Africa. Special Publication 1: Conservation Biology of Flamingo. Waterbirds Society, 23, 40-46.

[26] Wetlands International (2002) Waterbird Population Estimates. Third Edition, Wetlands International Global Series No. 12, Wageningen, The Netherlands.

[27] Birdlife International (2004) Threatened Birds of the World. CD-ROM. Birdlife International, Cambridge.

[28] Nonga, H.E., Mdegela, R.H., Lie, E., Sandvik, M. and Skaare, J.U. (2010) Socio-Economic Values of Wetland Re- 
sources around Lake Manyara, Tanzania: Assessment of Environmental Threats and Local Community Awareness on Environmental Degradation and Their Effects. Journal of Wetlands Ecology, 4, 83-101.

[29] IUCN-SSC (2008) International Single Species Action Plan for the Conservation of Lesser Flamingo: Techniacl Series No. 18 (CMS) and 34 (AEWA).

[30] Harper, D.M., Childress, R.B., Harper, M.M., Boar, R.R., Hickley, P., Mills, S.C., Otieno, N., Drane, T., Vareschi, E., Nasirwa, O., Mwatha, W.E., Darlington, J.P.E.C. and Escute-Gasulla, X. (2003) Aquatic Biodiversity and Saline Lakes: Lake Bogoria National Reserve, Kenya. Hydrobiologia, 500, 259-276. http://dx.doi.org/10.1023/A:1024722821407

[31] Vick, K. (2000). Kenya's Pink death, Washington Post Foreign Service. http://www.epa.gov/earlink1/earthlink/00janfeb.htm\#kenya

[32] Brown, L. (1959) The Mystery of the Flamingos. Country Life Ltd., London. United Kingdom.

[33] Grzimek, M. and Grzimek, B. (1960) Flamingos Censused in East Africa by Aerial Photography. Journal of Wildlife Management, 24, 215-217. http://dx.doi.org/10.2307/3796749

[34] Melack, J.M. (1978) Morphometric, Physics and Chemical Features of the Volcanic Crater Lakes of Western Uganda. Archaelogy Hydrolobiology, 84, 430-453.

[35] Tuite, C.H. (2000) The Distribution and Density of Lesser Flamingos in East Africa in Relation to Food Availability and Productivity. Water Birds, 23, 52-63. http://dx.doi.org/10.2307/1522147

[36] Tuite, C.H. (1979) Population Size, Distribution and Biomass Density of the Lesser Flamingos in the Eastern Rift Valley. Journal of Applied Ecology, 16, 765-775.

[37] Yanda, P.Z. and Madulu, N.F. (2005) Water Resource Management and Biodiversity Conservation in the Eastern Rift Valley Lakes. Northern Tanzania, Elsevier Ltd, Physics and Chemistry of the Earth, Parts A/B/C, 30, 717-725.

[38] UNEP (2005) One Planet Many People. Images of Africa’s Changing Lakes. Division of Early Warning and Assessment, United Nations Environmental Programme, Island Press, Washingto DC.

[39] TANAPA (2002) General Management Plan/Environmental Impact Assessment. Lake Manyara National Park, Tanzania.

[40] APHA (2005) Standard Methods for the Examination of Water and Waste Water. 21st Edition, American Public Health Association, Washington DC.

[41] Desikachary, T.V. (1959) Cyanophyta. Indian Council of Agricultural Research, New Delhi.

[42] Prescot, G.W. (1978) How to Know Freshwater Algae. 3rd Edition, Wm. C. Brown Company Publishers, Dubuque.

[43] Anagnostidis, K. and Komárek, J. (1985) Modern Approach to the Classification System of Cyanophytes.1—Introduction. Algological Studies. 38, 291-302.

[44] Anagnostidis, K. and Komárek, J. (1988) Modern Approach to the Classification System of Cyanophytes. 2-Oscillatoriales. Algological Studies, 50-53, 327-472.

[45] Komárek, J. and Anagnostidis, K. (1986) Modern Approach to the Classification System of Cyanophytes. 2-Chroococcales. Algological Studies, 43, 157-226.

[46] Hasle, G.R. and Syverstsen, E.E. (1997) Marine Diatoms. In: Tomas, C.R., Ed., Identifying Marine Phytoplankton, Academic Press, Waltham, 5-386. http://dx.doi.org/10.1016/B978-012693018-4/50004-5

[47] Andersen, P. and Throndsen, J. (2003) Estimating Cell Numbers. In: Hallegraeff, G.M., Anderson, D.M. and Cembella, A.D., Eds., Manual on Harmful Microalgae, UNESCO Publishing, Paris, 99-129.

[48] Nasirwa, O. (2000) Conservation Status of Flamingos in Kenya. Water Birds (Special Publication 1), $23,47-51$.

[49] Childress, B., Nagy, S., Hughes, B. and Abebe, Y.B. (2008) International Single Species Action Plan for the Conservation of Lesser Flamingos (Phoeniconaias minor). Convention of Migratory Species, Technical Series No. 18 AEWA Technical Series No. 34. Bonn. 61.

[50] Kaggwa, M.N., Gruber, M., Oduor, S.O. and Schagerl, M. (2013) A Detailed Time Series Assessment of the Diet of Lesser Flamingos: Further Explanation for Their Itinerant Behaviour. Hydrobiologia, 710, 83-93. http://dx.doi.org/10.1007/s10750-012-1105-1

[51] Vareschi, E. (1982) The Ecology of Lake Nakuru (Kenya) III; Abiotic Factors and Primary Production. Oecologia (Berl), 55, 81-101. http://dx.doi.org/10.1007/BF00386722

[52] Ballot, A., Krienitz, L., Kotut, K., Wiegand, C. and Pflugmacher, S. (2005) Cyanobacteria and Cyanobacterial Toxins in the Alkaline Crater Lakes Sonachi and Simbi, Kenya. Harmful Algae, 4, 139-150. http://dx.doi.org/10.1016/j.hal.2004.01.001

[53] Krienitz, L., Dadheech, P.K. and Kotut, K. (2013) Mass Developments of the Cyanobacteria Anabaenopsis and Cyanospira (Nostocales) in the Soda Lakes of Kenya: Ecological and Systematic Implications. Hydrobiologia, 703, 79-93. http://dx.doi.org/10.1007/s10750-012-1346-z 
[54] Romano, M., Barberis, I.M., Derlindati, E.J., Pagano, F., Marconi, P. and Arengo, F. (2009) Variation in the Abundance of Andean and Chilean Flamingos Wintering in Lowland Wetlands of Central Argentina in Two Contrasting Years. Flamingo Bulletin of the IUCN-SSC/Wetlands International, FLAMINGO SPECIALIST GROUP, 11-16.

[55] Tokuşoglu, Ö. and üUnal M.K. (2003) Biomass Nutrient Profiles of Microalgae: Spirulinaplatensis, Chlorella Vulgaris and Isochrisis galbana. Food Chemistry and Toxicology, 68, 1144-1148.

[56] Mühling, M., Belay, A. and Whitton, B.A. (2005) Variation in Fatty Acid Composition of Arthrospira (Spirulina) Strains. Journal of Applied Phycology, 17, 137-146. http://dx.doi.org/10.1007/s10811-005-7213-9

[57] Zieliñska, A. and Chojnacka, K. (2009) The Comparison of Biosorption of Nutritionally Significant Minerals in Singleand Multi-Mineral Systems by the Edible Microalga Spirulina sp. Journal of the Science of Food and Agriculture, 89, 2292-2301.

[58] Sileo, L., Grootenhuis, J.G., Tuite, C.H. and Hopcraft, J.B.D. (1979) Mycobacteriosis in the Lesser Flamingos of Lake Nakuru, Kenya. Journal of Wildlife Diseases, 15, 387-389. http://dx.doi.org/10.7589/0090-3558-15.3.387

[59] Graham, A.D. and Bell, R.H.V. (1969) Factors Affecting the Countability of Animals. East African Agricultural and Forestry Journal, Special Issue: 1996, 38-42.

[60] Raini, J. and Ngowe, N. (2009) Aerial Census of Lesser Flamingos (Phoeniconaias minor) on the Rift Valley Lakes of Northern Tanzania, January 2002. Flamingo Bulletin of the IUCN-SSC/Wetlands International, FLAMINGO SPECIALIST GROUP, 30-34.

[61] Madaka, T. (2007) Community Vulnerability and Adaptation to the Impacts of Climate Variability and Extremes on Wetlands: The Case of Simiyu Wetlands, Lake Victoria Basin' Tanzania. Unpublished MSc. Dissertation, University of Dar es Salaam, Dar es Salaam.

[62] Hudson, D.A. and Jones, R.G. (2002) Regional Climate Model Simulations of Present Day and Future Climates of Southern Africa. Technical Note No. 39: 41, United Kingdom Meteology Office, London.

[63] Lovejoy, E.T. and Hannah, L. (2005) Climate Change and Biodiversity. Yale University Press, New Haven.

[64] Rich, F. (1932) Phytoplankton from the Rift Valley Lakes in Kenya. Annals and Magazine of Natural History, 10, 233-262.

[65] Jenkins, P.M. (1957) The Filter Feeding and Food of the Flamingos. Philosophical Transactions of Royal Society London (B), 240, 401-493. http://dx.doi.org/10.1098/rstb.1957.0004

[66] Lugomela, C., Pratap, H.B. and Mgaya, Y.D. (2006) Cyanobacteria Blooms: A Possible Cause of Mass Mortality of Lesser Flamingos in Lake Manyara and Lake Big Momela, Tanzania. Harmful Algae, 5, 534-541. http://dx.doi.org/10.1016/j.hal.2005.10.001

[67] Ballot, A., Krienitz, L., Kotut, K., Wiegand, C., Metcalf, J.S., Codd, G.A. and Pflugmacher, S. (2004) Cyanobacteria and Cyanobacterial Toxins in Three Alkaline Rift Valley Lakes of Kenya-Lakes Bogoria, Nakuru and Elmentaita. Journal of Plankton Research, 26, 925-935. http://dx.doi.org/10.1093/plankt/fbh084

[68] Tuite, C.H. (1981). Standing Crop Densities and Distribution of Spirulina and Benthic Diatoms in East African Alkaline Saline Lakes. Freshwater Biology, 11, 345-360. 